Original research article

\title{
Does GD2 synthase (GD2S) detect cancer stem cells in blood samples of breast carcinomas?
}

\author{
Maryam Mansoori ${ }^{1,2}$, Isa Abdi Rad ${ }^{3}$, Alireza Mirzaei ${ }^{4}$, Kevin J. Tam ${ }^{5}$, Seyed Mohsen Hosseini ${ }^{6}$, \\ Rahim Mahmodlu ${ }^{7}$, Fatemeh Mansouri ${ }^{8}$, Leili Saeednejad Zanjani ${ }^{1}$, Zahra Madjd ${ }^{1,2}$ * \\ ${ }^{1}$ Iran University of Medical Sciences, Oncopathology Research Center, Tehran, Iran \\ ${ }^{2}$ Iran University of Medical Sciences, Faculty of Advanced Technologies in Medicine, Department of Molecular Medicine, Tehran, Iran \\ ${ }^{3}$ Urmia University of Medical Sciences, Cellular and Molecular Research Center, Urmia, Iran \\ ${ }^{4}$ Iran University of Medical Sciences, Shafa Orthopedic Hospital, Bone and Joint Reconstruction Research Center, Tehran, Iran \\ ${ }^{5}$ University of British Columbia, Vancouver Prostate Centre, Department of Urologic Sciences, Vancouver, Canada \\ ${ }^{6}$ Omid specialty and subspecialty Hospital, Oncology and Radiotherapy Ward, Urmia, Iran \\ ${ }^{7}$ Urmia University of Medical Sciences, Faculty of Medicine, Imam Khomeini Hospital, Department of Surgery, Urmia, Iran \\ ${ }^{8}$ Urmia University of Medical Sciences, Faculty of Medicine, Department of Genetics and Immunology, Urmia, Iran
}

\begin{abstract} (BC) patients. GD2S was higher in pre-chemotherapy blood samples compared to control samples. malignancy.

Keywords: Breast cancer; Cancer stem cell; Circulating cancer stem cell; ELISA; qRT-PCR

Highlights:

- GD2 Synthase (GD2S) is higher after chemotherapy (CHT) comparing pre- chemotherapy.

- Elevated GD2S after CHT is consistent with chemotherapy failure in CSC eradication.

- GD2S detection using qRT-PCR and ELISA may be used as a non-invasive method.
\end{abstract}

Introduction: Cancer stem cells (CSCs) are a theorized subset of cells within the tumor that is thought to drive disease recurrence and metastatic spread. The aim of this study is to investigate mRNA and protein levels of ganglioside GD2 synthase (GD2S), in breast cancer

Methods: 65 PBMCs of preoperative BC patients without chemotherapy were compared to PBMCs after chemotherapy and controls. Results: GD2S were significantly higher in BC patients after chemotherapy compared to pre-chemotherapy at both mRNA and protein.

Conclusions: Higher expression of GD2S in BC samples compared to healthy control indicates the potential utility of GD2S as a marker of

\section{Introduction}

Breast cancer $(\mathrm{BC})$ is the most common malignancy and the fifth cause of death for cancer in women worldwide (Azubuike et al., 2018). It is estimated that there will be 284,200 new cases and 44,130 deaths from BC in the United States in 2021 (Siegel et al., 2021). The clinically-available regimens for the treatment of BC include first, second, and third generation non-specific cytotoxic agents, endocrine therapies, and specific biological agents (Anampa et al., 2015). Despite the arsenal of therapeutics available for the treatment of $\mathrm{BC}$, the prognosis for many $\mathrm{BC}$ patients remains bleak due to the high rate of cancer recurrence and the emergence of multiple drug resistance (MDR) after initial chemotherapy treatments (Taylor and Jabbarzadeh, 2017).
The purported existence of cancer stem cells (CSCs) potentially explains the many shortcomings of current cancer treatment modalities. The CSC hypothesis suggests that a small subset of quiescent tumor-initiating cells is at the apex of a tumor cell hierarchy which gives rise to the entire tumor cell population. CSCs are characterized by slow cell cycling, the expression of specific stem cell surface markers, and the capability to maintain tumors in vivo (Dzobo et al., 2016). CSCs display multiple unique features that facilitate tumor formation and metastatic spread (Chen et al., 2013).

Quiescent slow-growing CSCs are thought to be more invasive than their proliferating CSC counterparts which are believed to contribute to bulk tumor formation (Chen et al., 2016; De Francesco et al., 2018). By virtue of their slow growth, quiescent CSCs circumvent the actions of standard chemotherapies therein presenting a path to tumor recurrence

\footnotetext{
* Corresponding author: Zahra Madjd, Iran University of Medical Sciences (IUMS), Oncopathology Research Center, Hemmat Street (Highway), Next to Milad Tower, Tehran, Iran; e-mail: Zahra.madjd@yahoo.com; Majdjabari.z@iums.ac.ir http://doi.org/10.32725/jab.2021.019

Submitted: 2020-11-28 • Accepted: 2021-09-03 • Prepublished online: 2021-09-16

J Appl Biomed 19/4: 181-189 • EISSN 1214-0287 • ISSN 1214-021X

(c) 2021 The Authors. Published by University of South Bohemia in České Budějovice, Faculty of Health and Social Sciences.

This is an open access article under the CC BY-NC-ND license.
} 
(Mathews, 2013; Owens and Naylor, 2013; Visvader and Lindeman, 2012). Consequently, careful consideration for the existence of CSCs and their possible roles in cancer etiology and progression needs to be taken. If CSCs fulfil a role in this regard, CSCs would present an attractive target for novel therapies and their detection could be used a diagnostic method.

Increasing evidence suggests that a small subset of circulating tumor cells (CTCs) also bears resemblance to CSCs based on their ability to give rise to tumors and thus could be considered blood-born functional CSCs or circulating cancer stem cells (CCSCs), which are potential therapeutic targets for preventing disease progression (Agnoletto et al., 2019; Katoh et al., 2015; Yang et al., 2015).

Evaluation of CCSCs and their biomarkers in the peripheral blood of tumor patients may be of greater clinical importance in such things as disease monitoring compared to local assessment (Mirzaei et al., 2016). Liquid biopsies, the analyses of biomarkers in a non-solid biological tissues such as blood, hold significant advantages over traditional biopsies. The detection of CTCs in blood is one of the most widely-used applications of liquid biopsies. Research into CTCs may play a key role in improving our understanding of the metastatic process, tumor dynamics during treatment, and disease progression (Grolz et al., 2018; Marrugo-Ramirez et al., 2018; Pawlikowska et al., 2019; Saarenheimo et al., 2019).

Putative biomarkers for identifying and tracking CCSCs have been proposed in different cancers including $B C$ such as CD24, CD44, CD133, CXCR4, ALDH1, ABCG2, and c-Met (Aktas et al., 2009; Baba et al., 2009; Balic et al., 2006; Hermann et al., 2007; Ho et al., 2007; Inoue et al., 2010; Kasimir-Bauer et al., 2012; Li et al., 2011; Nian et al., 2011; Pang et al., 2010; Seigel et al., 2005; Singh et al., 2004; Sun and Wang, 2011; Tirino et al., 2011, 2013; Todaro et al., 2014; Wang et al., 2009; Zhang et al., 2012). Nevertheless, more thorough and expansive research is warranted to identify the most effective markers for the isolation of viable CCSCs (Yang et al., 2015).

Ganglioside GD2 is a sialic acid-containing glycosphingolipid that has important clinical and pathological implications. It plays a crucial role both in physiological and pathological processes and can drive proliferation, neoangiogenesis, immune-escape and invasion (Fleurence et al., 2017). Ganglioside GD2 is a marker for BC stem cells (BCSCs), promotes tumorigenesis, and represents a new CSC-specific cell surface marker (Battula et al., 2012). It has been demonstrated that complex gangliosides, including GD2, play a key role in tumor growth and metastasis, by mediating cell proliferation, migration, adhesion and angiogenesis (Cazet et al., 2012).

GD2 and GD3, together with their common upstream glycosyltransferases, GD3 synthase (GD3S) and GD2 synthase (GD2S), maintain a stem cell phenotype in breast CSCs (Liang et al., 2013). It has been shown that small interfering RNAs against GD2S efficiently reduces c-Met phosphorylation and reverses the proliferative phenotype (Cazet et al., 2012; Liang et al., 2017). The reduction of GD2 expression by GD2S knockdown reduced mammosphere formation and cell motility, completely abrogated tumor formation in vivo, and reverted the CSC phenotype into a non-CSC phenotype (Lefebvre and Delannoy, 2019).

The basic steps of metastasis include local invasion, intravasation, survival in blood or lymph circulation, extravasation, and colonization (Massague et al., 2017). As CSCs are candidate mediators of metastasis, tracing CSCs in the blood of cancer patients would be highly informative (Mirzaei et al., 2015). To this point, we hypothesized that GD2S in blood circulation might reflect the presence of CCSCs in BC and we therefore set out to determine if levels of GD2S in peripheral blood of BC patients are elevated compared to non-cancer patients. Doing so would provide support for GD2S as a CSC marker.

This work aims to assess whether GD2S is detectable in blood samples of BC patients. Furthermore, as current markers for BCSCs are non-specific this work endeavours to identify GD2S as a specific marker for BCSCs for potential applications in monitoring early metastasis in BC patients. To our knowledge, this is the largest study examining GD2S in human blood samples.

\section{Materials and methods}

\section{Patients characteristics and samples}

Based on previous studies and using statistical formulas, a total of 65 BC patients who had undergone diagnostic surgery were included in this study. The patients were referred to the Imam Khomeini Hospital in Urmia, Iran, in the time period 2015-2016. These patients comprised various subtypes of $\mathrm{BC}$, including invasive ductal carcinoma, invasive lobular carcinoma, comedo type, micro papillary, metaplastic carcinoma, fibromatosis like carcinoma, and ductal carcinoma in situ (Fitzgibbons and Connolly, 2019). Fresh blood was collected from $\mathrm{BC}$ patients before and $\sim 6$ months following $\mathrm{BC}$ chemotherapy. Sixty-five control blood samples were also collected from healthy individuals without a history of cancer who were referred to the same hospital for reasons other than cancer. $B C$ patients were followed after resection of tumors and their medical archival records were retrieved to obtain clinicopathological parameters, including age, tumor type, histologic grade, tumor stage, lymphatic invasion, vascular invasion, and tumor size. Tumors were staged and graded according to TNM classification protocol (Gregoire et al., 2014). The main chemotherapy regimen consisted of intravenous infusion of CAF (Cyclophosphamide, Adriamycin and Fluorouracil). If two blood samples (pre and after chemotherapy) could not been collected, that sample was excluded from the study. For each sample to be included all the samples must be achieved and the patients should not undergo any treatment for breast cancer before diagnostic surgery.

Each patient was assigned an ID number to maintain anonymity and investigator was blinded to the group allocation. This study was approved by the Research Ethics Committee of Iran University of Medical Sciences (Ref No: IR.IUMS. rec.1394.26452). Informed consent was obtained from all individual participants included in the study.

\section{RNA isolation, cDNA synthesis, and quantitative real- time PCR (qRT-PCR) analysis of fresh blood samples}

GD2S mRNA expression level was assessed using qRT-PCR to compare GD2S expression before and after chemotherapy and also to control samples. Peripheral blood mononuclear cells (PBMCs) were also isolated from blood and stored in freezing medium (Roche, USA) at $-80{ }^{\circ} \mathrm{C}$ and subsequently extracted for RNA. Total RNA was extracted from PBMC using RNX-plus solution, chloroform, isopropanol, and ethanol (all from Afragen biotech, Iran) according to the manufacturer's standard procedures. Complementary DNA (cDNA) was synthesized from $2 \mu \mathrm{g}$ total RNA using First Strand cDNA Synthesis Kit (Yekta tajhiz Azma, Iran). qRT-PCR was performed using iQ5 real-time PCR detection system (Bio-Rad, USA) using the following cycling parameters: 1 cycle at $95{ }^{\circ} \mathrm{C}$ for $3 \mathrm{~min}$, then 40 cycles at $95{ }^{\circ} \mathrm{C}$ for $40 \mathrm{~s}$ and $60{ }^{\circ} \mathrm{C}$ for $40 \mathrm{~s}$. Each assay was done in triplicate and positive and negative controls were in- 
cluded in each run. Comparative gene expression analysis was performed using the $\Delta \Delta C t$ method with normalization to the reference gene GAPDH (Laurent et al., 2010; Mahata et al., 2015; Yeh et al., 2016). GAPDH F: CATGAGAAGTATGACAACAGCCT and R: AGTCCTTCCACGATACCAAAGT. GD2S F: GACAAGCCAGAGCGCGTTA and R: TACTTGAGACACGGCCAGGTT (Ahmed, 2014; Cheung and Cheung 2001; Martinez et al., 2007).

\section{Enzyme-linked immunosorbent assay (ELISA) of fresh blood samples}

Sandwich ELISA was performed to detect GD2S protein within mononuclear cells of $\mathrm{BC}$ patients and for confirmation of the results of qRT-PCR. Highly specific quantitative human B4GALNT1 sandwich ELISA kit (MBS109442, USA) was applied to measure the expression of GD2S in fresh blood samples according to the manufacturer's instructions. $50 \mu \mathrm{l}$ standard solution was added to each standard well, $50 \mu \mathrm{l}$ sample to each sample well, and $50 \mu \mathrm{l}$ sample diluent to each blank/control well. $100 \mu \mathrm{l}$ of HRP-conjugate reagent was added to each well and incubated for $60 \mathrm{~min}$ at $37^{\circ} \mathrm{C}$. The plate was washed 4 times. $50 \mu \mathrm{l}$ chromogen solution $\mathrm{A}$, and chromogen solution $B$ were added to each well. Then, it was protected from light and incubated for $15 \mathrm{~min}$ at $37^{\circ} \mathrm{C}$. $50 \mu$ stop solution was added to each well. The absorbance was determined at $595 \mathrm{~nm}$ using an absorbance microplate reader within 15 min after adding the stop solution. GD2S concentrations were calculated based on a standard curve. Data were represented as mean $\mathrm{ng} / \mathrm{ml}$ of $\mathrm{GD} 2 \mathrm{~S} \pm \mathrm{SD}$ of three experiments.

\section{Statistical analysis}

Data were analyzed using the statistical software SPSS (version 20.0; IBM Corp, USA). All experiments were performed in triplicate. Normality test was done to check the normal distribution of data. Mean level of GD2S expression in fresh blood samples and control blood samples was compared using Kruskal-Wallis and Mann-Whitney $U$ test. Pearson's $\chi^{2}$ was used to assess the association between gene and protein expression levels of GD2S and clinicopathological parameters of BC patients. A $p$-value of $<0.05$ was considered statistically significant.

\section{Results}

\section{Expression of GD2S before chemotherapy compared to healthy control}

Blood samples from BC patients, pre-chemotherapy and before diagnostic surgery were collected. mRNA and protein levels were assessed using qRT-PCR and ELISA and compared to levels in non-cancer patients. The results showed that the GD2S mRNA levels in pre-chemotherapy BC patients was 2.22-fold higher than in control blood samples $(P<0.001)$. Similarly, ELISA showed a significant increase in circulating GD2S protein in pre-chemotherapy BC patients compared to control blood samples (3.58-fold, $P=0.002$ ) (Fig. 1).

\section{Expression of GD2S after chemotherapy compared to pre-chemotherapy}

Next, we assessed the effect of BC chemotherapy on the mRNA and protein levels of GD2S. Post-chemotherapy blood samples showed a significant increase (4.19-fold, $P<0.001)$ in GD2S mRNA expression compared to pre-chemotherapy blood samples. Likewise, circulating levels of GD2S protein were elevated

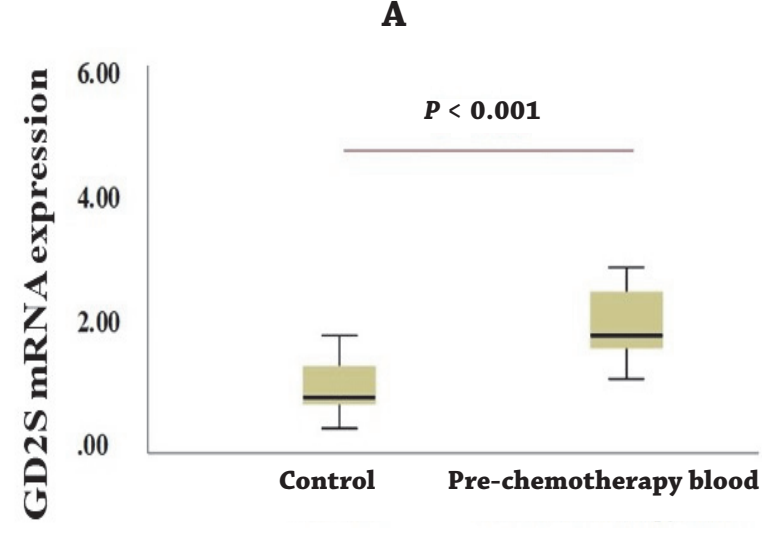

B

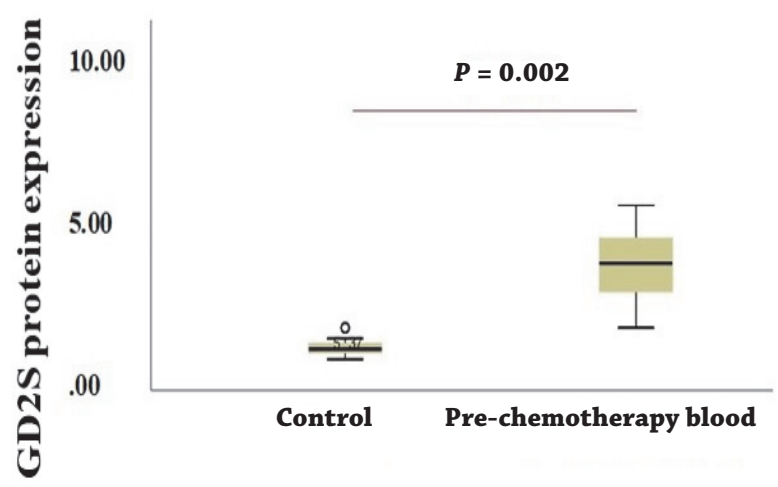

Fig. 1. GD2 synthase (GD2S) expression in pre-chemotherapy blood samples of $B C(B C)$ patients and control blood samples. (A) Expression levels of GD2S mRNA in pre-chemotherapy blood samples was significantly higher than control blood samples (2.2-fold). (B) GD2S protein levels were significantly higher in prechemotherapy blood samples than control blood samples (3.58-fold). Data are represented as mean \pm SD $(n=3$ each).

in $\mathrm{BC}$ patients after chemotherapy compared to pre- chemotherapy as shown by ELISA (2.5-fold, $P<0.0001)$ (Fig. 2).

\section{The association of GD2S expression with clinicopathological characteristics of $B C$ patients}

As described above, qRT-PCR was performed in order to ascertain the levels of GD2S mRNA in patients. Associations were then made between GD2S mRNA levels and clinicopathological parameters. In pre-chemotherapy BC patients, expression of GD2S was significantly higher in blood from those with higher stages of disease $(P=0.04)$. We also observed higher expression of GD2S in BC patients whose tumors invade to lymph nodes $(P=0.02)$. Similarly, in $B C$ patients who have undergone chemotherapy, higher expression of GD2S was observed in cases of higher stage disease (stage III \& IV) $(P=0.03)$ (Table 1$)$. The normality test was carried out using Shapiro-Wilk's Test on raw data. The results of normality test showed that the data are normally distributed; therefore, the mean of data was used as the cut-off value, and the data were classified into two groups: low expression as group 1 and high expression as group 2. 
A

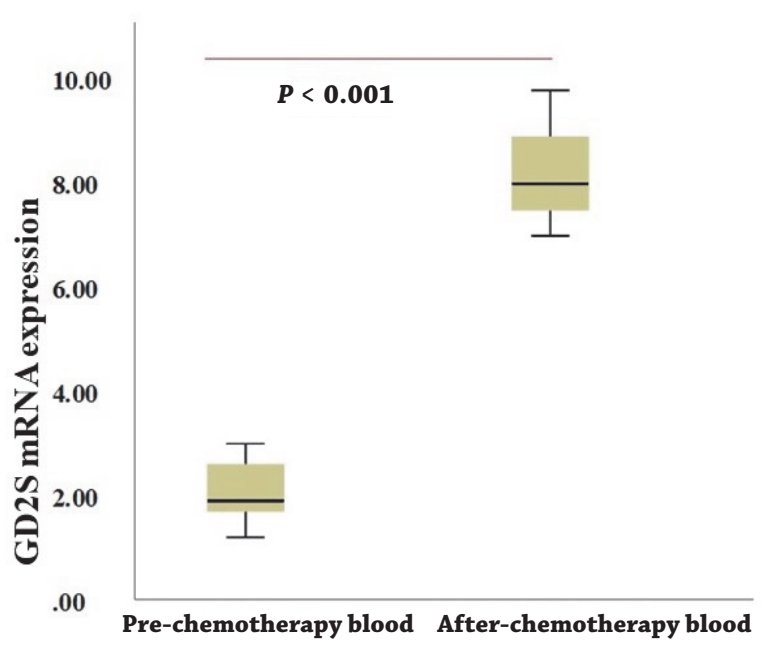

B

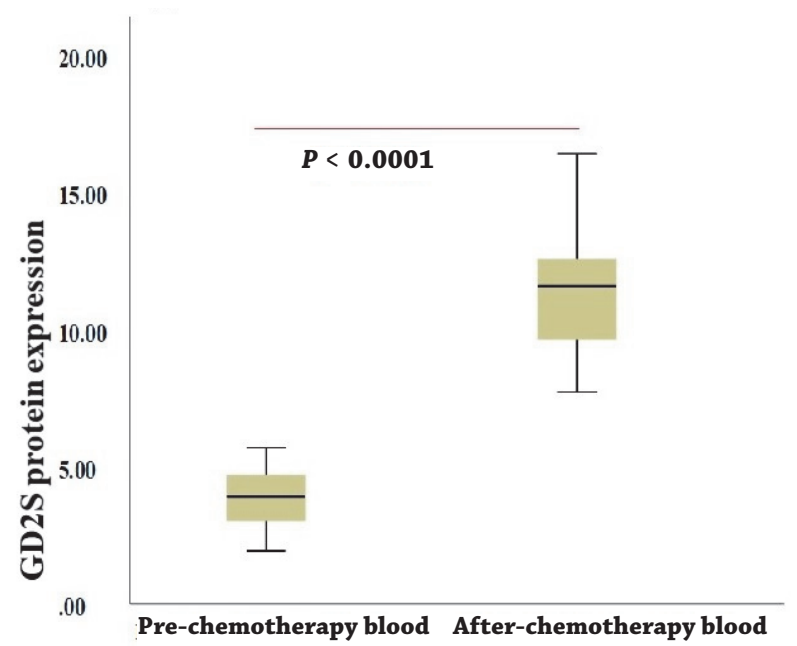

Fig. 2. GD2 synthase (GD2S) expression in blood samples before and after BC (BC) chemotherapy. (A) Expression levels of GD2S mRNA was significantly higher after chemotherapy compared to pre-chemotherapy (4.19-fold). (B) GD2S protein levels were significantly higher in postchemotherapy blood samples than in pre-chemotherapy blood samples (2.5-fold). Data is represented as mean \pm SD $(n=3$ each).

Table 1. The association between mRNA expression of GD2 synthase (GD2S) and clinicopathological parameters in blood samples in patients with $\mathrm{BC}(\mathrm{BC})\left(P\right.$-value; Pearson's $\chi^{2}$ test)

\begin{tabular}{|c|c|c|c|c|c|c|c|}
\hline \multirow{3}{*}{$\begin{array}{l}\text { Clinicopathological } \\
\text { parameters }\end{array}$} & \multicolumn{7}{|c|}{ GD2 synthase expression } \\
\hline & \multirow{2}{*}{$\begin{array}{c}\text { Total } \\
\text { number (\%) }\end{array}$} & \multicolumn{2}{|c|}{ Pre-chemotherapy } & \multirow[b]{2}{*}{$P$-value } & \multicolumn{2}{|c|}{ After chemotherapy } & \multirow[b]{2}{*}{$P$-value } \\
\hline & & $\begin{array}{c}\text { Low } \\
\text { expression }\end{array}$ & $\begin{array}{l}\text { High } \\
\text { expression }\end{array}$ & & $\begin{array}{l}\text { Low } \\
\text { expression }\end{array}$ & $\begin{array}{l}\text { High } \\
\text { expression }\end{array}$ & \\
\hline \multicolumn{8}{|l|}{ Age (years) } \\
\hline$\leq$ Mean age & $36(55.4)$ & $13(36.1)$ & $23(63.9)$ & 0.12 & $12(33.3)$ & $24(66.7)$ & 0.51 \\
\hline$>$ Mean age & $29(44.6)$ & $18(62.1)$ & $11(37.9)$ & & $12(41.4)$ & $17(58.6)$ & \\
\hline \multicolumn{8}{|l|}{ Tumor types } \\
\hline Invasive ductal carcinoma & $33(50.8)$ & $16(48.5)$ & $17(51.5)$ & \multirow{7}{*}{0.7} & $10(30.3)$ & $23(69.7)$ & \multirow{7}{*}{0.4} \\
\hline Ductal carcinoma in situ & $9(13.8)$ & $6(66.7)$ & $3(33.3)$ & & $4(44.4)$ & $5(55.6)$ & \\
\hline Comedo-type & $7(10.8)$ & $3(42.9)$ & $4(57.1)$ & & $3(42.9)$ & $4(57.1)$ & \\
\hline Metaplastic & $6(9.2)$ & $4(66.7)$ & $2(33.3)$ & & $3(50.0)$ & $3(50.0)$ & \\
\hline Invasive lobular carcinoma & $6(9.2)$ & $3(50.0)$ & $3(50.0)$ & & $2(33.3)$ & $4(66.7)$ & \\
\hline Fibromatosis-like & $3(4.6)$ & $1(33.3)$ & $2(66.7)$ & & $2(66.7)$ & $1(33.3)$ & \\
\hline Micro papillary & $1(1.5)$ & $0(0.0)$ & $1(100.0)$ & & $0(0.0)$ & $1(100.0)$ & \\
\hline \multicolumn{8}{|l|}{ Histological grade } \\
\hline 1 & $24(36.9)$ & $13(54.2)$ & $11(45.8)$ & \multirow{3}{*}{0.62} & $9(37.5)$ & $15(62.5)$ & \multirow{3}{*}{0.85} \\
\hline 2 & $25(38.5)$ & $13(52.0)$ & $12(48.0)$ & & $12(48.0)$ & $13(52.0)$ & \\
\hline 3 & $16(24.6)$ & $5(31.2)$ & $11(68.8)$ & & $3(18.8)$ & $13(81.2)$ & \\
\hline \multicolumn{8}{|l|}{ Tumor stage } \\
\hline I & $14(21.5)$ & $13(92.9)$ & $1(7.1)$ & \multirow{3}{*}{0.04} & $10(71.4)$ & $4(28.6)$ & \multirow{3}{*}{0.03} \\
\hline II & $11(16.9)$ & $6(54.5)$ & $5(45.5)$ & & $4(36.4)$ & $7(63.6)$ & \\
\hline III \& IV & $40(61.5)$ & $12(30.0)$ & $28(70.0)$ & & $10(25.0)$ & $30(75.0)$ & \\
\hline \multicolumn{8}{|l|}{ Lymphatic invasion } \\
\hline Yes & $36(55.4)$ & $11(30.6)$ & $25(69.4)$ & \multirow[t]{2}{*}{0.02} & $13(54.2)$ & $23(56.1)$ & \multirow[t]{2}{*}{0.54} \\
\hline No & $29(44.6)$ & $20(69.0)$ & $9(31.0)$ & & $11(45.8)$ & $18(43.9)$ & \\
\hline \multicolumn{8}{|l|}{ Vascular invasion } \\
\hline Yes & $20(30.8)$ & $9(27.3)$ & $11(34.4)$ & \multirow[t]{2}{*}{0.17} & $7(29.2)$ & $13(31.7)$ & \multirow[t]{2}{*}{0.21} \\
\hline No & $45(69.2)$ & $24(72.7)$ & $21(65.6)$ & & $17(7.8)$ & $28(68.3)$ & \\
\hline \multicolumn{8}{|l|}{ Tumor size $(\mathrm{cm})$} \\
\hline$\leq$ Mean size & $41(63.1)$ & $17(60.7)$ & $24(39.3)$ & \multirow[t]{2}{*}{0.46} & $27(65.9)$ & $14(34.1)$ & \multirow[t]{2}{*}{0.36} \\
\hline$>$ Mean size & $24(36.9)$ & $11(64.9)$ & $13(35.1)$ & & $14(58.3)$ & $10(41.7)$ & \\
\hline
\end{tabular}

$P$-value of $<0.05$ was considered statistically significant. 
Circulating GD2S protein in pre-chemotherapy BC patients was associated with increased mean age of patients $(P=0.002)$, more advanced stages of the disease $(P=0.003)$ and invasion to the lymph node $(P=0.001)$, similarly, the higher expression of GD2S was associated with higher tumor stages $(P=0.03)$ in blood samples after BC therapies (Table 2$)$.

GD2S mRNA and protein levels were correlated with higher stages of the disease and lymphatic invasion in pre-chemotherapy blood samples and with higher stages of the disease in after chemotherapy blood samples of BC patients.

\section{Discussion}

The incidence of BC is increasing worldwide (da Silva, 2017) but the available markers are not sensitive or specific enough to detect at early disease (Prabavathy et al., 2018). The CSC theory potentially explains the ineffectiveness of conventional cancer therapy (Sphyris et al., 2015). Several markers including CD24-/low/CD44+ (Liang et al., 2013), ALDH1, CD133, SOX2, CK5, alpha-6 integrin/CD49f, beta-1 integrin/CD29, or lack of ER (Cazet et al., 2012) have been identified for BCSC detection. While many BCSC markers have been put forward, the minimal set of bona fide BCSC markers remains to be elu- cidated (Chen et al., 2013; Dehghan Esmatabadi et al., 2018; Fleurence et al., 2017; Prabavathy et al., 2018). Recently, ganglioside GD2 was identified as a new CSC-specific cell surface marker in breast cancer. GD2 identifies CSCs which are capable of initiating tumors with as few as 10 GD2+ cells (Battula et al., 2012). GD2 has certain advantages compared to other tumor-associated gangliosides since this glycolipid is highly expressed in tumor cells which is not expressed at all or expressed at a very low level in normal cells (Doronin et al., 2014; Nazha et al., 2020) . In normal non-malignant tissues, GD2 expression is mostly restricted to neurons, skin melanocytes, and peripheral nerves (Ahmed and Cheung, 2014; Cavdarli et al., 2020; Sait and Modak, 2017), therefore, it is less likely that GD2 in the PBMC may be related to other hematopoietic cell types including, T cells, B cells, NK cells, macrophages, monocytes, and other myeloid cells.

The high expression of GM2/GD2 synthase leads to the accumulation of GD2 in neuroblastoma cells (Kwon et al., 2017). GD2 levels are dramatically higher in BCSCs than in non-CSCs; knockdown of GD2S significantly reduces GD2 expression, causing a phenotype change from CSC to a non-CSC (Liang et al., 2013; Sait and Modak, 2017). In normal breast tissues, complex gangliosides are absent or expressed at very low level and silencing of the GM2/GD2 synthase efficiently reduces

Table 2. The association between protein expression of GD2 synthase (GD2S) and clinicopathological parameters in blood samples in patients with BC (BC) (P-value; Pearson's $\chi^{2}$ test)

GD2 synthase expression

\begin{tabular}{|c|c|c|c|c|c|c|c|}
\hline \multirow{3}{*}{$\begin{array}{l}\text { Clinicopathological } \\
\text { parameters }\end{array}$} & \\
\hline & \multirow{2}{*}{$\begin{array}{c}\text { Total } \\
\text { number (\%) }\end{array}$} & \multicolumn{2}{|c|}{$\begin{array}{l}\text { Pre-chemotherapy } \\
\text { blood samples }\end{array}$} & \multirow{2}{*}{$P$-value } & \multicolumn{2}{|c|}{$\begin{array}{l}\text { After chemotherapy } \\
\text { blood samples }\end{array}$} & \multirow{2}{*}{$P$-value } \\
\hline & & $\begin{array}{c}\text { Low } \\
\text { expression }\end{array}$ & $\begin{array}{c}\text { High } \\
\text { expression }\end{array}$ & & $\begin{array}{c}\text { Low } \\
\text { expression }\end{array}$ & $\begin{array}{c}\text { High } \\
\text { expression }\end{array}$ & \\
\hline \multicolumn{8}{|l|}{ Age (years) } \\
\hline$\leq$ Mean age & $36(55.4)$ & $26(72.2)$ & $10(27.8)$ & \multirow[t]{2}{*}{0.002} & $18(50.0)$ & $18(50.0)$ & \multirow[t]{2}{*}{0.28} \\
\hline$>$ Mean age & $29(44.6)$ & $11(37.9)$ & $18(62.1)$ & & $15(51.7)$ & $14(48.3)$ & \\
\hline \multicolumn{8}{|l|}{ Tumor types } \\
\hline Invasive ductal carcinoma & $33(50.8)$ & $23(69.7)$ & $10(30.3)$ & \multirow{7}{*}{0.8} & $14(42.4)$ & $19(57.6)$ & \multirow{7}{*}{0.8} \\
\hline Ductal carcinoma in situ & $9(13.8)$ & $7(77.8)$ & $2(22.2)$ & & $7(77.8)$ & $2(22.2)$ & \\
\hline Comedo-type & $7(10.8)$ & $2(28.6)$ & $5(71.4)$ & & $5(71.4)$ & $2(28.6)$ & \\
\hline Metaplastic & $6(9.2)$ & $6(100.0)$ & $0(0.0)$ & & $2(33.3)$ & $4(66.7)$ & \\
\hline Invasive lobular carcinoma & $6(9.2)$ & $6(100.0)$ & $0(0.0)$ & & $3(50.0)$ & $3(50.0)$ & \\
\hline Fibromatosis-like & $3(4.6)$ & $1(33.3)$ & $2(66.7)$ & & $0(0.0)$ & $3(100.0)$ & \\
\hline Micro papillary & $1(1.5)$ & $0(0.0)$ & $1(100.0)$ & & $1(100.0)$ & $0(0.0)$ & \\
\hline \multicolumn{8}{|l|}{ Histological grade } \\
\hline 1 & $24(36.9)$ & $15(62.5)$ & $9(37.5)$ & \multirow{3}{*}{0.11} & $13(54.2)$ & $11(45.8)$ & \multirow{3}{*}{0.20} \\
\hline 2 & $25(38.5)$ & $15(60.0)$ & $10(40.0)$ & & $10(40.0)$ & $15(60.0)$ & \\
\hline 3 & $16(24.6)$ & $8(50.0)$ & $8(50.0)$ & & $10(62.5)$ & $6(37.5)$ & \\
\hline \multicolumn{8}{|l|}{ Tumor stage } \\
\hline I & $14(21.5)$ & $13(92.9)$ & $1(7.1)$ & \multirow{3}{*}{0.003} & $9(64.3)$ & $5(35.7)$ & \multirow{3}{*}{0.03} \\
\hline II & $11(16.9)$ & $8(72.7)$ & $3(27.3)$ & & $9(81.8)$ & $2(18.2)$ & \\
\hline III \& IV & $40(61.5)$ & $17(42.5)$ & $23(57.5)$ & & $16(40.0)$ & $24(60.0)$ & \\
\hline \multicolumn{8}{|l|}{ Lymphatic invasion } \\
\hline Yes & $36(55.4)$ & $11(30.6)$ & $25(69.4)$ & \multirow[t]{2}{*}{0.001} & $17(47.2)$ & $19(52.8)$ & \multirow[t]{2}{*}{0.11} \\
\hline No & $29(44.6)$ & $21(72.4)$ & $8(27.6)$ & & $16(55.2)$ & $13(44.8)$ & \\
\hline \multicolumn{8}{|l|}{ Vascular invasion } \\
\hline Yes & $20(30.8)$ & $10(32.3)$ & $10(29.4)$ & \multirow[t]{2}{*}{0.80} & $8(40.0)$ & $12(60.0)$ & \multirow[t]{2}{*}{0.22} \\
\hline No & $45(69.2)$ & $21(67.7)$ & $24(70.6)$ & & $25(55.6)$ & $20(44.4)$ & \\
\hline \multicolumn{8}{|l|}{ Tumor size $(\mathrm{cm})$} \\
\hline$\leq$ Mean size & 41 (63.1) & $23(56.1)$ & $18(43.9)$ & \multirow[t]{2}{*}{0.68} & $21(51.2)$ & $20(48.8)$ & \multirow[t]{2}{*}{0.11} \\
\hline$>$ Mean size & $24(36.9)$ & $9(37.5)$ & $15(62.5)$ & & $12(50.0)$ & $12(50.0)$ & \\
\hline
\end{tabular}

$P$-value of $<0.05$ was considered statistically significant. 
the expression of GD2 (Cheung et al., 2003). GD2 synthesis is dependent on the key enzyme GD2S (Furukawa et al., 2002; Yoshida et al., 2020) and GD2S transcript is found to correlate with both progression-free survival and overall survival. Further to this, GD2S predicts adjuvant treatment efficacy in neuroblastoma and holds prognostic potential (Chow et al., 2012). Our goal was to confirm GD2S as a marker for assessing the response of $\mathrm{BC}$ patients to conventional therapies as well as to provide a CSC marker for diagnostic and monitoring purposes. To this end, we determined GD2S levels in the largest cohort of human BC fresh blood samples to date and correlate circulating GD2S levels to clinicopathologic characteristics in $\mathrm{BC}$ patients. By comparison, the majority of previous studies on GD2S and ganglioside GD2 focused on BC cell lines (Cheung et al., 2003; Liang et al., 2013). One similar study on patients' samples studied 12 BC tissue samples (Sphyris et al., 2015). To our knowledge no other study has evaluated the association of ganglioside GD2 or GD2S with clinicopathologic characteristics in patients.

Molecular detection of GD2 synthase transcript may have potential value in detecting rare tumor cells (Lo Piccolo et al., 2001). Our findings indicate that GD2S mRNA level is higher in blood samples of BC patients compared to healthy control. Furthermore, our data show higher levels of GD2S mRNA in the blood of BC patients after chemotherapy compared to before chemotherapy. The higher expression of GD2S after chemotherapy could be explained by an enrichment of CSCs following chemotherapy due to inherent resistance of CSCs to chemotherapy. If this were true, chemotherapy, while shrinking bulk tumor size, would give rise to an outgrowth of the rare subpopulation of CSC in both tumor tissue and blood circulation of BC patients (Lichtinghagen et al., 2002; Pawlik and Keyomarsi, 2004; Sarro et al., 2010). In our case, the increase CSCs may have manifested in higher observed levels of GD2S. CSC enrichment has been described in several tumor types including lung cancer (Hamilton and Olszewski, 2013), ovarian cancer (Abubaker et al., 2013) and colorectal cancer (Dylla et al., 2008). Our results are in line with previous studies showing that conventional therapies affect only rapidly dividing bulk tumor cells while failing to eliminate CSCs due to their drug resistance (Abubaker et al., 2013; Hamilton and Olszewski, 2013; Pawlik and Keyomarsi, 2004).

It is worth noting that CSCs may play important roles in metastatic spread via the circulatory and lymphatic system. Consistent with this notion, our study confirmed that the levels of GD2S were elevated in cases with lymph node involvement. By the same virtue, CSCs are associated with more advanced stages of cancer. As we would expect, high GD2S was also associated with more advanced stages of BC.

Since the mRNA level of a gene does not necessarily predict its protein level (Lichtinghagen et al., 2002; Sarro et al., 2010; Shebl et al., 2010; Taquet et al., 2009), the protein level of GD2S was assessed along with its mRNA.

As the study design was a retrospective design and data collection could not be applicable for our study in this step, in the current study, ER/PR/Her2 information was available only for 10 out of 65 samples.

Meanwhile, possible sources may exist for GD2 synthase expression, but the higher level of GD2 expression in breast cancer patients compared to normal cases may represent the tumoral source of GD2 that entered the blood circulation as a matter of cancer progression. Given that GD2 is associated with BCSCs we make the assertion that GD2S is associated with BCSCs. In our previous study by immunohistochemistry, we showed that higher GD2 expression was mainly found in the patients with advanced histological grade, presence of lymph node invasion, the larger size of tumors, and more aggressive tumors behaviour. Furthermore, in combination with other potential breast CSC markers, including CD44 and CD24, we found that GD2-high/CD44-high/CD24- cells were frequently observed in breast cancer samples with positive lymph node involvement and larger size (Mansoori et al., 2019). While GD2 was significantly expressed in breast tumors, a very low expression level of GD2 was confirmed in normal cells. The cells responsible for GD2 expression could possess the tumoral origin of more aggressive states, which possibly may pass to blood circulation for initiating more advanced stages; therefore, it is supposed that CTCs can be the most appropriate cells in PBMC as the origin of GD2.

In a similar study in colorectal cancer ( $C R C)$, circulating tumor cells also showed higher mRNA and protein expression of specific CSC markers, DCLK1 and Lgr5, in tumoral tissues compared to normal adjacent margins, indicating the higher expression level in patients with higher grade and stages of disease and patients who underwent neoadjuvant chemo radiotherapy. The local expression pattern of DCLK1 and Lgr5 was also in accordance with their expression level in circulation. Considering the over-expression of CSC markers in circulating blood of CRC patients compared to controls, the findings emphasize the presence of CSCs in the blood of these patients, which might be attributed to their clinical and pathological characteristics and may lead to applying in future clinical implications (Mirzaei et al., 2015, 2016).

Indeed, to define the source of CSC markers in blood circulation, cell sorting using multiple CSC markers is the most probable method. However, CSCs constitute a small fraction of tumor cells. A very few CSCs enter the blood circulation to complete metastasis cascade, and we only take $10 \mathrm{ml}$ of blood as a representative sample. As a result, we need a high-throughput cell sorting method whose sensitivity is comparable to PCR. Determining whether cells bearing GD2S also co-express other canonical BCSC markers will also be informative. Whether GD2S can assist in stratifying BC sub-types should also be further examined. The limitation of our study was the unavailability of the patients' survival information, as having this data would help in expanding the findings and also determining the prognosis of the disease.

To close, increased GD2S marker expression was observed in tumors of more advanced stages. Considering that GD2S is highly expressed by tumor cells but not by normal cells, GD2S is an appealing anti-tumor therapeutic target. Furthermore, anti-GD2S therapies could be used in combination with conventional therapies.

\section{Conclusions}

This study may provide valuable therapeutic insight for clinical applications in the treatment of BC. In summary GD2S is higher after chemotherapy compared to pre-chemotherapy in the blood of BC patients. As GD2 is indicative of a BCSC, we make the extrapolation that GD2S also marks BCSCs. Thus, elevated GD2S following chemotherapy is consistent with the supposed ineffectiveness of current chemotherapies in eradicating CSCs in BC. This work also indicates that detection of GD2S using qRT-PCR and ELISA from liquid biopsy materials may be used for patient monitoring and response to therapy as a non-invasive clinical method. 


\section{Acknowledgements}

The authors would like to thank for staffs of Department of Pathology, Iran University of Medical Sciences and Imam Khomeini Hospital of Urmia, respectively.

\section{Funding}

This study was supported by a grant from Iran University of Medical Sciences (Grant \# 94-03-87-26452).

\section{Conflict of interests}

The authors report no conflict of interests.

\section{Ethics approval}

The study was approved by Iran University of Medical Sciences Human Research Ethics Committee in Iran (Ref No: IR.IUMS. rec.1394.26452). All the procedures were performed in accordance with the 1964 Helsinki Declaration and its later amendments.

\section{References}

Abubaker K, Latifi A, Luwor R, Nazaretian S, Zhu H, Quinn MA, et al. (2013). Short-term single treatment of chemotherapy results in the enrichment of ovarian cancer stem cell-like cells leading to an increased tumor burden. Mol Cancer 12: 24. DOI: $10.1186 / 1476-4598-12-24$.

Agnoletto C, Corra F, Minotti L, Baldassari F, Crudele F, Cook WJJ, et al. (2019). Heterogeneity in Circulating Tumor Cells: The Relevance of the Stem-Cell Subset. Cancers (Basel) 11(4): 483. DOI: $10.3390 /$ cancers 11040483.

Ahmed M, Cheung NK (2014). Engineering anti-GD2 monoclonal antibodies for cancer immunotherapy. FEBS Lett 588(2): 288-297. DOI: 10.1016/j.febslet.2013.11.030.

Ahmed R (2014). Selective Elimination of Malignant Melanoma Using the Novel Anti-tumor Agents, OSW-1 and PEITC. The University of Texas MD Anderson Cancer Center UTHealth Graduate School of Biomedical Sciences Dissertations and Theses.

Aktas B, Tewes M, Fehm T, Hauch S, Kimmig R, Kasimir-Bauer S (2009). Stem cell and epithelial-mesenchymal transition markers are frequently overexpressed in circulating tumor cells of metastatic breast cancer patients. Breast Cancer Res 11(4): R46. DOI: $10.1186 / \mathrm{bcr} 2333$

Anampa J, Makower D, Sparano JA (2015). Progress in adjuvant chemotherapy for breast cancer: an overview. BMC Med 13: 195. DOI: 10.1186/s12916-015-0439-8.

Azubuike SO, Muirhead C, Hayes L, McNally R (2018). Rising global burden of breast cancer: the case of sub-Saharan Africa (with emphasis on Nigeria) and implications for regional development: a review. World J Surg Oncol 16(1): 63. DOI: 10.1186/s12957018-1345-2.

Baba T, Convery PA, Matsumura N, Whitaker RS, Kondoh E, Perry T, et al. (2009). Epigenetic regulation of CD133 and tumorigenicity of CD133+ ovarian cancer cells. Oncogene 28(2): 209-218. DOI: 10.1038/onc.2008.374.

Balic M, Lin H, Young L, Hawes D, Giuliano A, McNamara G, et al. (2006). Most early disseminated cancer cells detected in bone marrow of breast cancer patients have a putative breast cancer stem cell phenotype. Clin Cancer Res 12(19): 5615-5621. DOI: 10.1158/1078-0432.CCR-06-0169.

Battula VL, Shi Y, Evans KW, Wang RY, Spaeth EL, Jacamo RO, et al. (2012). Ganglioside GD2 identifies breast cancer stem cells and promotes tumorigenesis. J Clin Invest 122(6): 2066-2078. DOI: $10.1172 / J C I 59735$

Cavdarli S, Delannoy P, Groux-Degroote S (2020). O-acetylated Gangliosides as Targets for Cancer Immunotherapy. Cells 9(3): 741. DOI: $10.3390 /$ cells9030741.

Cazet A, Bobowski M, Rombouts Y, Lefebvre J, Steenackers A, Popa I, et al. (2012). The ganglioside G(D2) induces the constitutive activation of c-Met in MDA-MB-231 breast cancer cells expressing the G(D3) synthase. Glycobiology 22(6): 806-816. DOI: 10.1093/ glycob/cws049.

Chen K, Huang YH, Chen JL (2013). Understanding and targeting cancer stem cells: therapeutic implications and challenges. Acta Pharmacol Sin 34(6): 732-740. DOI: 10.1038/aps.2013.27.

Chen W, Dong J, Haiech J, Kilhoffer MC, Zeniou M (2016). Cancer Stem Cell Quiescence and Plasticity as Major Challenges in Cancer Therapy. Stem Cells Int 2016: 1740936. DOI: 10.1155/2016/1740936.

Cheung IY, Cheung NK (2001). Quantitation of marrow disease in neuroblastoma by real-time reverse transcription-PCR. Clin Cancer Res 7(6): 1698-1705.

Cheung IY, Lo Piccolo MS, Kushner BH, Kramer K, Cheung NK (2003). Quantitation of GD2 synthase mRNA by real-time reverse transcriptase polymerase chain reaction: clinical utility in evaluating adjuvant therapy in neuroblastoma. J Clin Oncol 21(6): 1087-1093. DOI: 10.1200/JCO.2003.02.055.

Chow EK, Fan LL, Chen X, Bishop JM (2012). Oncogene-specific formation of chemoresistant murine hepatic cancer stem cells. Hepatology 56(4): 1331-1341. DOI: 10.1002/hep.25776.

da Silva A (2017). Investigating c-FLIP Suppression and TRAIL Treatment in Breast Cancer. PhD Thesis. Cardiff University.

De Francesco EM, Sotgia F, Lisanti MP (2018). Cancer stem cells (CSCs): metabolic strategies for their identification and eradication. Biochem J 475(9): 1611-1634. DOI: 10.1042/ BCJ20170164.

Dehghan Esmatabadi MJ, Movahedi Motlagh F, Etemadzadeh A, Hajigholami S (2018). The Most Well-known Markers of CSCs and Their Role in Growth of Tumors, Drug Resistance and Metastasis. J Human Gen Genom 2(1): e65253. DOI: 10.5812/jhgg.65253.

Doronin II, Vishnyakova PA, Kholodenko IV, Ponomarev ED, Ryazantsev DY, Molotkovskaya IM, et al. (2014). Ganglioside GD2 in reception and transduction of cell death signal in tumor cells. BMC Cancer 14: 295. DOI: 10.1186/1471-2407-14-295.

Dylla SJ, Beviglia L, Park IK, Chartier C, Raval J, Ngan L, et al. (2008). Colorectal cancer stem cells are enriched in xenogeneic tumors following chemotherapy. PLoS One 3(6): e2428. DOI: 10.1371/journal.pone.0002428.

Dzobo K, Senthebane DA, Rowe A, Thomford NE, Mwapagha LM, Al-Awwad N, et al. (2016). Cancer Stem Cell Hypothesis for Therapeutic Innovation in Clinical Oncology? Taking the Root Out, Not Chopping the Leaf. OMICS 20(12): 681-691. DOI: 10.1089/omi.2016.0152.

Fitzgibbons P, Connolly J (2019). Protocol for the Examination of Biopsy Specimens From Patients With Invasive Carcinoma of the Breast. College of American Pathologists (CAP).

Fleurence J, Fougeray S, Bahri M, Cochonneau D, Clemenceau B, Paris F, et al. (2017). Targeting O-Acetyl-GD2 Ganglioside for Cancer Immunotherapy. J Immunol Res 2017: 5604891. DOI: 10.1155/2017/5604891.

Furukawa K, Takamiya K, Furukawa K (2002). Beta1,4-Nacetylgalactosaminyltransferase - GM2/GD2 synthase: a key enzyme to control the synthesis of brain-enriched complex gangliosides. Biochim Biophys Acta 1573(3): 356-362. DOI: 10.1016/s0304-4165(02)00403-8.

Gregoire V, Ang K, Budach W, Grau C, Hamoir M, Langendijk JA, et al. (2014). Delineation of the neck node levels for head and neck tumors: a 2013 update. DAHANCA, EORTC, HKNPCSG, NCIC CTG, NCRI, RTOG, TROG consensus guidelines. Radiother Oncol 110(1): 172-181. DOI: 10.1016/j.radonc.2013.10.010.

Grolz D, Hauch S, Schlumpberger M, Guenther K, Voss T, SprengerHaussels M, Oelmuller U (2018). Liquid Biopsy Preservation Solutions for Standardized Pre-Analytical Workflows-Venous Whole Blood and Plasma. Curr Pathobiol Rep 6(4): 275-286. DOI: 10.1007/s40139-018-0180-z.

Hamilton G, Olszewski U (2013). Chemotherapy-induced Enrichment of Cancer Stem Cells in Lung Cancer. J Bioanal Biomed S9: 003. DOI: 10.4172/1948-593X.S9-003.

Hermann PC, Huber SL, Herrler T, Aicher A, Ellwart JW, Guba M, et al. (2007). Distinct populations of cancer stem cells determine tumor growth and metastatic activity in human pancreatic cancer. Cell Stem Cell 1(3): 313-323. DOI: 10.1016/j.stem.2007.06.002. 
Ho MM, Ng AV, Lam S, Hung JY (2007). Side population in human lung cancer cell lines and tumors is enriched with stem-like cancer cells. Cancer Res 67(10): 4827-33. DOI: 10.1158/0008-5472. CAN-06-3557.

Inoue A, Takahashi H, Harada H, Kohno S, Ohue S, Kobayashi K, et al. (2010). Cancer stem-like cells of glioblastoma characteristically express MMP-13 and display highly invasive activity. Int J Oncol 37(5): 1121-1131. DOI: 10.3892/ ijo_00000764.

Kasimir-Bauer S, Hoffmann O, Wallwiener D, Kimmig R, Fehm T (2012). Expression of stem cell and epithelial-mesenchymal transition markers in primary breast cancer patients with circulating tumor cells. Breast Cancer Res 14(1): R15. DOI: 10.1186/bcr3099.

Katoh S, Goi T, Naruse T, Ueda Y, Kurebayashi H, Nakazawa T, et al. (2015). Cancer stem cell marker in circulating tumor cells: expression of CD44 variant exon 9 is strongly correlated to treatment refractoriness, recurrence and prognosis of human colorectal cancer. Anticancer Res 35: 239-244.

Kwon KM, Chung TW, Kwak CH, Choi HJ, Kim KW, Ha SH, et al. (2017). Disialyl GD2 ganglioside suppresses ICAM-1-mediated invasiveness in human breast cancer MDA-MB231 cells. Int J Biol Sci 13(3): 265-275. DOI: 10.7150/ijbs.16903.

Laurent VE, Otero LL, Vazquez V, Camarero S, Gabri MR, Labraga M, et al. (2010). Optimization of molecular detection of GD2 synthase mRNA in retinoblastoma. Mol Med Rep 3(2): 253-259. DOI: 10.3892/mmr_00000248.

Lefebvre T, Delannoy P (2019). Disrupting membrane lipids composition promotes tumorigenesis: the other dark side of cholesterol and the potential implication of gangliosides. Transl Cancer Res 7(Suppl. 5): S587-S590. DOI: 10.21037/ tcr.2018.04.26.

Li C, Wu J-J, Hynes M, Dosch J, Sarkar B, Welling TH, et al. (2011). c-Met is a marker of pancreatic cancer stem cells and therapeutic target. Gastroenterology 141(6): 2218-2227.e5. DOI: 10.1053/j. gastro.2011.08.009.

Liang YJ, Ding Y, Levery SB, Lobaton M, Handa K, Hakomori SI (2013). Differential expression profiles of glycosphingolipids in human breast cancer stem cells vs. cancer non-stem cells. Proc Natl Acad Sci U S A 110(13): 4968-4973. DOI: 10.1073/ pnas.1302825110.

Liang YJ, Wang CY, Wang IA, Chen YW, Li LT, Lin CY, et al. (2017). Interaction of glycosphingolipids GD3 and GD2 with growth factor receptors maintains breast cancer stem cell phenotype. Oncotarget 8(29): 47454-47473. DOI: 10.18632/oncotarget.17665.

Lichtinghagen R, Musholt PB, Lein M, Romer A, Rudolph B, Kristiansen G, et al. (2002). Different mRNA and protein expression of matrix metalloproteinases 2 and 9 and tissue inhibitor of metalloproteinases 1 in benign and malignant prostate tissue. Eur Urol 42(4): 398-406. DOI: $10.1016 /$ s03022838(02)00324-x

Lo Piccolo MS, Cheung NK, Cheung IY (2001). GD2 synthase: a new molecular marker for detecting neuroblastoma. Cancer 92(4): 924-931. DOI: 10.1002/1097-0142(20010815)92:4<924::aidcncr1402>3.0.co;2-o.

Mahata B, Banerjee A, Kundu M, Bandyopadhyay U, Biswas K (2015). TALEN mediated targeted editing of GM2/GD2-synthase gene modulates anchorage independent growth by reducing anoikis resistance in mouse tumor cells. Sci Rep 5: 9048. DOI: 10.1038/ srep09048.

Mansoori M, Roudi R, Abbasi A, Abolhasani M, Abdi Rad I, Shariftabrizi A, Madjd Z (2019). High GD2 expression defines breast cancer cells with enhanced invasiveness. Exp Mol Pathol 109: 25-35. DOI: 10.1016/j.yexmp.2019.05.001.

Marrugo-Ramirez J, Mir M, Samitier J (2018). Blood-Based Cancer Biomarkers in Liquid Biopsy: A Promising Non-Invasive Alternative to Tissue Biopsy. Int J Mol Sci 19(10): 2877. DOI: $10.3390 / \mathrm{ijms} 19102877$.

Martinez C, Hofmann TJ, Marino R, Dominici M, Horwitz EM (2007). Human bone marrow mesenchymal stromal cells express the neural ganglioside GD2: a novel surface marker for the identification of MSCs. Blood 109(10): 4245-4248. DOI: 10.1182/ blood-2006-08-039347.
Massague J, Batlle E, Gomis RR (2017). Understanding the molecular mechanisms driving metastasis. Mol Oncol 11(1): 3-4. DOI: 10.1002/1878-0261.12024.

Mathews L (Ed.) (2013). DNA Repair of Cancer Stem Cells. Heidelberg: Springer.

Mirzaei A, Madjd Z, Kadijani AA, Tavakoli-Yaraki M, Modarresi MH, Verdi J, et al. (2016). Evaluation of circulating cellular DCLK1 protein, as the most promising colorectal cancer stem cell marker, using immunoassay based methods. Cancer Biomark 17(3): 301-311. DOI: 10.3233/CBM-160642.

Mirzaei A, Tavoosidana G, Modarressi MH, Rad AA, Fazeli MS, Shirkoohi R, et al. (2015). Upregulation of circulating cancer stem cell marker, DCLK1 but not Lgr5, in chemoradiotherapytreated colorectal cancer patients. Tumour Biol 36(6): 4801-4810. DOI: 10.1007/s13277-015-3132-9.

Nazha B, Inal C, Owonikoko TK (2020). Disialoganglioside GD2 Expression in Solid Tumors and Role as a Target for Cancer Therapy. Front Oncol 10: 1000. DOI: 10.3389/fonc.2020.01000.

Nian WQ, Chen FL, Ao XJ, Chen ZT (2011). CXCR4 positive cells from Lewis lung carcinoma cell line have cancer metastatic stem cell characteristics. Mol Cell Biochem 355(1-2): 241-248. DOI: 10.1007/s11010-011-0860-z.

Owens TW, Naylor MJ (2013). Breast cancer stem cells. Front Physiol 4: 225. DOI: 10.3389/fphys.2013.00225.

Pang R, Law WL, Chu AC, Poon JT, Lam CS, Chow AK, et al. (2010). A subpopulation of CD26+ cancer stem cells with metastatic capacity in human colorectal cancer. Cell Stem Cell 6(6): 603-615. DOI: 10.1016/j.stem.2010.04.001.

Pawlik TM, Keyomarsi K (2004). Role of cell cycle in mediating sensitivity to radiotherapy. Int J Radiat Oncol Biol Phys 59(4): 928-942. DOI: 10.1016/j.ijrobp.2004.03.005.

Pawlikowska P, Faugeroux V, Oulhen M, Aberlenc A, Tayoun T, Pailler E, et al. (2019). Circulating tumor cells (CTCs) for the noninvasive monitoring and personalization of non-small cell lung cancer (NSCLC) therapies. J Thorac Dis 11(Suppl 1): S45-S56. DOI: $10.21037 /$ jtd.2018.12.80.

Prabavathy D, Swarnalatha Y, Ramadoss N (2018). Lung cancer stem cells-origin, characteristics and therapy. Stem Cell Investig 5: 6. DOI: $10.21037 /$ sci.2018.02.01.

Saarenheimo J, Eigeliene N, Andersen H, Tiirola M, Jekunen A (2019). The Value of Liquid Biopsies for Guiding Therapy Decisions in Non-small Cell Lung Cancer. Front Oncol 9: 129. DOI: 10.3389/ fonc.2019.00129.

Sait S, Modak S (2017). Anti-GD2 immunotherapy for neuroblastoma. Expert Rev Anticancer Ther 17(10): 889-904. DOI: 10.1080/14737140.2017.1364995.

Sarro SM, Unruh TL, Zuccolo J, Sanyal R, Luider JM, AuerGrzesiak IA, et al. (2010). Quantification of CD20 mRNA and protein levels in chronic lymphocytic leukemia suggests a post-transcriptional defect. Leuk Res 34(12): 1670-1673. DOI: 10.1016/j.leukres.2010.06.031.

Seigel GM, Campbell LM, Narayan M, Gonzalez-Fernandez F (2005). Cancer stem cell characteristics in retinoblastoma. Mol Vis 11: 729-737.

Shebl FM, Pinto LA, Garcia-Pineres A, Lempicki R, Williams M, Harro C, et al. (2010). Comparison of mRNA and protein measures of cytokines following vaccination with human papillomavirus-16 L1 virus-like particles. Cancer Epidemiol Biomarkers Prev 19(4): 978-981. DOI: 10.1158/1055-9965.EPI-10-0064.

Siegel RL, KD Miller, HE Fuchs, Jemal A (2021). Cancer Statistics, 2021. CA Cancer J Clin 71(1): 7-33. DOI: 10.3322/caac.21654.

Singh SK, Hawkins C, Clarke ID, Squire JA, Bayani J, Hide T, et al. (2004). Identification of human brain tumour initiating cells. Nature 432(7015): 396-401. DOI: 10.1038/nature03128.

Sphyris N, Sarkar TR, Battula VL, Andreeff M, Mani SA (2015). GD2 and GD3 synthase: novel drug targets for cancer therapy. Mol Cell Oncol 2(3): e975068. DOI: 10.4161/23723556.2014.975068.

Sun S, Wang Z (2011). Head neck squamous cell carcinoma c-Met(+) cells display cancer stem cell properties and are responsible for cisplatin-resistance and metastasis. Int J Cancer 129: 2337-2348. DOI: 10.1002/ijc.25927. 
Taquet N, Dumont S, Vonesch JL, Hentsch D, Reimund LM, Muller CD (2009). Differential between protein and mRNA expression of CCR7 and SSTR5 receptors in Crohn's disease patients. Mediators Inflamm 2009: 285812. DOI: $10.1155 / 2009 / 285812$.

Taylor WF, Jabbarzadeh E (2017). The use of natural products to target cancer stem cells. Am J Cancer Res 7(7): 1588-1605.

Tirino V, Desiderio V, Paino F, De Rosa A, Papaccio F, Fazioli F, et al. (2011). Human primary bone sarcomas contain CD133+ cancer stem cells displaying high tumorigenicity in vivo. FASEB J 25(6): 2022-2030. DOI: 10.1096/f.10-179036.

Tirino V, Desiderio V, Paino F, De Rosa A, Papaccio F, La Noce M, et al. (2013). Cancer stem cells in solid tumors: an overview and new approaches for their isolation and characterization. FASEB J 27(1): 13-24. DOI: 10.1096/f.12-218222.

Todaro M, Gaggianesi M, Catalano V, Benfante A, Iovino F, Biffoni M, et al. (2014). CD44v6 is a marker of constitutive and reprogrammed cancer stem cells driving colon cancer metastasis. Cell Stem Cell 14(3): 342-356. DOI: 10.1016/j.stem.2014.01.009.

Visvader JE, Lindeman GL (2012). Cancer stem cells: current status and evolving complexities. Cell Stem Cell 10(6): 717-728. DOI: 10.1016/j.stem.2012.05.007.
Wang YH, Li F, Luo B, Wang XH, Sun HC, Liu S, et al. (2009). A side population of cells from a human pancreatic carcinoma cell line harbors cancer stem cell characteristics. Neoplasma 56(5): 371-378. DOI: 10.4149/neo_2009_05_371.

Yang MH, Imrali A, Heeschen C (2015). Circulating cancer stem cells: the importance to select. Chin J Cancer Res 27(5): 437-449. DOI: 10.3978/j.issn.1000-9604.2015.04.08.

Yeh SC, Wang PY, Lou YW, Khoo KH, Hsiao M, Hsu TL, et al. (2016). Glycolipid GD3 and GD3 synthase are key drivers for glioblastoma stem cells and tumorigenicity. Proc Natl Acad Sci U S A 113(20): 5592-5597. DOI: 10.1073/pnas.1604721113.

Yoshida H, Koodie L, Jacobsen K, Hanzawa K, Miyamoto Y, Yamamoto M (2020). B4GALNT1 induces angiogenesis, anchorage independence growth and motility, and promotes tumorigenesis in melanoma by induction of ganglioside GM2/GD2. Sci Rep 10: 1199. DOI: 10.1038/s41598-019-57130-2.

Zhang SS, Han ZP, Jing YY, Tao SF, Li TJ, Wang H, et al. (2012). CD133(+)CXCR4(+) colon cancer cells exhibit metastatic potential and predict poor prognosis of patients. BMC Med 10: 85. DOI: 10.1186/1741-7015-10-85. 